\title{
An Introduction of Regulatory Focus Theory and Its Recently Related Researches
}

\author{
Wenlong Cui, Maolin Ye \\ Institute of Human Resources Management, School of Management, Jinan University, Guangzhou, China \\ Email:wenlongcui@hotmail.com
}

How to cite this paper: Cui, W. L., \& Ye, M. L. (2017). An Introduction of Regulatory Focus Theory and Its Recently Related Researches. Psychology, 8, 837-847. https://doi.org/10.4236/psych.2017.86054

Received: March 28, 2017

Accepted: April 27, 2017

Published: April 30, 2017

Copyright $\odot 2017$ by authors and Scientific Research Publishing Inc. This work is licensed under the Creative Commons Attribution International License (CC BY 4.0).

http://creativecommons.org/licenses/by/4.0/

\begin{abstract}
Based on the previous theory and research that have shown that people have two distinct self-regulatory focuses, Higgins put forward Regulatory Focus Theory (RFT) extending the basic hedonic principle that people are motivated to approach pleasure and avoid pain, and in the purpose of a new explanation of people's motivation, revealed that how humans approach the positive target and avoid the negative. The theory distinguished two different orientations: prevention focus and promotion focus. They are different in various aspects such as different needs, characterization of the target, focuses of the results, and emotional arousal. The article introduces the theory of Regulatory Focus, and its nature and different types, and also describes the most recently related researches in organizational behavior.
\end{abstract}

\section{Keywords}

Regulatory Focus, Prevention Focus, Promotion Focus

\section{Introduction}

All along, the researchers stressed "approaching pleasure and avoiding pain" and hedonic principle's domination in motivational research. However, this principle does not explain how people can avoid disadvantages; in addition, it can not explain some seemingly contradictory phenomenon. For example, why are positive feedback sometimes improving performance and sometimes hindering? Why the goal expectation and the maximization of the target value not always improve the individual's commitment to the goal? Higgins (1997) proposed Regulatory Focus Theory (RFT) extending the basic hedonic principle that people are motivated to approach pleasure and avoid pain, and in the purpose of a new explanation of people's motivation, revealed that how humans approach the positive target and avoid the negative. China's scholars have made a brief review of RTF (Yao \& Yue, 2009). But little is known about its internal regulatory 
mechanism, as well as the latest empirical research results in their study. This paper discussed the property and mechanism of regulatory focus and sorted out the recent research results of the RTF, with a goal to help Chinese scholars further carry out relevant researches to discover some new findings.

\section{Regulatory Focus Theory}

\subsection{Conception of Regulatory Focus}

While previous theory and research have considered the relationship between employees' emotional experience and their work attitudes and behaviors (George \& Brief, 1996), organizational scholars have devoted much less attention to the psychological processes that affect the nature and magnitude of people's emotional experience. Besides traditional psychology holds that human behavior follows the principle of "hedonism" and tends to maximize happiness and minimize pain, and act on the basis of the law of "escape the pain and pursuit of happiness". But Higgins (1997) argued that the principle of "hedonism" can't be used to explain the difference in the use of strategies in the "escape the pain and pursuit of happiness" behavior of human beings. To explore the essence of the motivation of human behavior. Higgins (1997) proposed Regulatory Focus Theory (RFT), in the purpose of a new explanation of human's motivation. Regulatory Focus Theory is specifically concerned with the nature and magnitude of people's emotional experience and, by extension, may help elucidate their work attitudes and behaviors.

Self-regulation refers to the process in which people seek to align themselves (i.e., their behaviors and self-conceptions) with appropriate goals or standards. According to Regulatory Focus Theory, our survival depends on two basic needs: security needs and growth needs. There are two different regulatory system corresponding to the two different need to meet. When individuals' needs are met, they feel happy, when needs cannot be met, the individual will feel pain. Security-related control system is called prevention focus, positively adjust the behavior of keep away from punishment, make people tend to focus on the negative. Nurturance-related is called promotion focus, promotes the positive adjustment of rewarded activity. These regulatory focuses run in different ways to meet the individual needs. Individuals holding promotion focus tend to be in the pursuit of "ideal" self, care for "hope" and "aspiration", and always pay more attention to their growth and self-realization. Individuals holding prevention focus tend to be complacent and conservative, and always pay more attention to "duty" and "responsibility", care for "required" and "safety". Higgins believes promotion focus is the result of strong ideal, "taking or not" situation and growth needs; Prevention focus is the result of intense obligations, "loss or not" situation and security needs.

\subsection{Property of Regulatory Focus}

The nature of regulatory focus is defined as chronic and situational. Chronic regulatory focus is a kind of personality tendency gradually formed in the 
process of growth which is a kind of long-term regulatory focus. Situational regulatory focus also called short-term regulatory focus is a kind of personality tendency induced by specific situation and task frame information.

Higgins $(1997,1998)$ holds that chronic regulatory focus is a stable tendency of self-regulation influenced by parents' parenting style in the process of their growth. Parents who paid more attention on the development of children's growth needs tend to cultivate children's initiative and autonomy, then promotion focus formed. Meanwhile parents who paid more attention on the protection of their children from harm incline to mode a higher sense of safety and responsibility, then prevention focus formed.

As to the forming of situational regulatory focus, situational inducements that emphasize the need for growth, the realization of the ideal and the potential benefits are more likely to induce promotion regulatory focus; situational inducements that emphasize safety needs, performance obligations and potential losses are more likely to induce prevention regulatory focus (Higgins, 1997, 1998).

In summary, regulatory focus can be affected by the individual's self-regulatory history and also can be affected by the current situation or task; The former is a long-term personality trait, while the latter is manifested as a temporary motivational orientation (Higgins, 1997).

\subsection{Types of Regulatory Focus}

Higgins (1997, 1998) suggested that there are important differences in the process through which people approach pleasure and avoid pain. Higgins proposed two distinct hedonic self-regulatory systems, one in which people have a promotion focus and the other in which they have a prevention focus. When promotion focused, people are motivated by growth and development needs in which they attempt to bring their actual selves (their behaviors and self-conceptions) in alignment with their ideal selves (self-standards based on wishes and aspirations of how they would like to be). When prevention focused, people are responsive to security needs in which they try to match their actual selves with their ought selves (self-standards based on felt duties and responsibilities). Dholakia, Gopinath, Bagozzi \& Nataraajan (2006) further distinguish their difference.

First, behavior is regulated through different means in the two focus. In the promotion focus, the individual's actions are governed by ideals; that is aspirations and accomplishments that he or she would like to achieve and strive for. In contrast, the prevention focus regulates behavior through a preoccupation on oughts; that is, duties and responsibilities.

Second, there are differences in how goal pursuit is framed in the two focus. Promotion focused individuals favor approach strategies, so they frame goal pursuit in terms of gains and non-gains; prevention focused individuals do so with respect to losses and non-losses because of their preference for avoidance strategic means. Under a promotion focus, the individual's strategic inclination 
is to approach matches to end states he or she would like to achieve (Higgins, 1999). Such individuals are more eager to avoid errors of omission (i.e., missing an emerging opportunity to accomplish something), resulting in an initial inclination to act. In contrast, a prevention focus fosters a tendency to avoid mismatches to end states he or she would like to attain, with an orientation toward maintaining the status quo and shielding oneself from losses. Such individuals therefore prefer cognitive or behavioral courses that avoid errors of commission (i.e., making mistakes). These differences have been shown to result in a more explorative information processing style by promotion focused individuals, more openness to change.

The third difference between the regulatory focus is motivational differences. Prior research has shown that promotion focused individuals have higher motivation levels than prevention focused individuals. This difference is evident in greater persistence in goal pursuit by promotion focused individuals, greater ability to bounce back and perform after a failure experience rather than quitting, greater capacity to change plans and use alternative strategies during goal pursuit, and higher standards of attainment that raise performance in effortful tasks (Higgins, 2001) relative to prevention focused individuals.

Then, what is the relationship between prevention focus and promotion focus? In this regard, there are two main viewpoints in the academic circles. One is that the two are mutually inhibitory and the other is the two cannot exist independently (Sengupta \& Zhou, 2007). For example, if the promotion focus is stimulated, the focus of prevention will be automatically suppressed. Another view is that they are independent of each other (Higgins et al., 2001). They argue that the RFT is closely related to Gray's (1990) self-regulatory system. Among them, the promotion focus is similar to the behavioral arousal system, the focus of prevention is similar to behavioral inhibition system. Behavioral arousal system controls desire motivation, and are more sensitive to positive results; behavioral inhibition system is in control of aversive motivation and more sensitive to negative outcomes. Owing to that behavioral arousal system and behavioral inhibition system each represent different physiological structures of the nervous system, the sensitivity of both is assumed to be independent of each other. So promotion focus and prevention focus should also be independent of each other.

\section{Research Status in $0 B$}

\subsection{Influencing Factors of Regulatory Focus}

Based on the multi-level perspective, this paper argues that the main factors affecting the regulatory focus include two levels: the group and the individual.

Influencing factors in group level mainly include role models, group safety climate, leadership style and behavior.

Role Modeling. Lockwood et al. (2002) point out that role models can have an impact on the regulatory focus of others. Individuals who have a promotion focus tend to be influenced by positive model behavior. So they have a desire to close action strategy to enhance their motivation and to achieve their goals. In- 
dividuals who have a prevention focus tend to be influenced by negative model behavior. So they will use vigilance and avoidance strategy in order to ensure safety, no damage and strengthen the motivation to avoid risks.

Group Safety Climate. Wallace and Chen (2006) discuss the intrinsic mechanism of group safety climate's influence on the impact of individual production performance and safety performance from the perspective of regulatory focus. Through a survey of 254 employees in the work team, we found that the safety climate can significantly predict the promotion focus and prevention focus.

Leadership Style and Behavior. Kark and Van-Dijk (2007) found that the transformational and charismatic leadership is more likely to motivate subordinates' prevention focus, while transactional leadership is more likely to motivate subordinates' prevention focus.

Neubert et al. (2008) further found that the structure of the leadership will enhance the prevention focus of subordinates, while service leadership promote the subordinates promotion focus. Brockner and Higgins (2001) firstly pointed out that the leadership as a meaning maker, may use the specific types of language and symbols to affect the regulatory focus of subordinates. The more words of the leaders focus on the ideal, the more likely they are to stimulate the subordinates' promotion focus, and to encourage the subordinates to pursue the ideal selves. The more focus on responsibility, obligation, and accuracy, the more likely they are to motivate subordinates prevention focus, and encourage subordinates to pursue more ought selves.

As to the individual factors are concerned, it mainly includes three aspects: personality, emotion and goal orientation.

Personality. Some researchers tested the connection between personality factors and regulatory focus, they found that self-esteem, extraversion and openness to experience were positively predicted to promotion focus, while negatively predict prevention focus (Gorman et al., 2012; Vaughn, Baumann, \& Klemann, 2008); The sense of responsibility can positively predict promotion focus as well as prevention focus (Wallace \& Chen, 2006), while anxiety and neuroticism negatively predict promotion focus, while positively predict prevention focus (Gorman et al., 2012). In addition, a meta-analysis performed by Gorman et al. (2012) shows that optimism is also an important factor in promoting the promotion focus.

Emotion. Summerville and Roese (2008) found that the relationship between positive emotion, negative emotion and regulation focus was very close. Positive emotions promote the promotion focus, negative emotions promote prevention focus, the conclusion is also confirmed by Gorman (2012) and Lanaj (2012).

Goal Orientation. The main purpose of these studies is to explore the relationship between learning goal orientation, performance goal orientation and regulation focus. A meta-analysis of Gorman et al. (2012) and Lanaj (2012) showed that learning goal orientation will promote promotion focus, performance goal orientation will enhance prevention focus. However, Johnson et al. (2011) also found that learning goal orientation can enhance the prevention fo- 
cus through laboratory research and field research.

\subsection{Effects of Regulatory Focus}

Organizational Commitment. Organizational commitment is a kind of employee's commitment, responsibility and obligations to the organization, which includes three aspects: emotional commitment, continuous commitment and normative commitment. Meyer, Becker and Vandenberghe (2004) discussed the influences of regulatory focus on organizational commitment from both internal and external motivation of individual behavior. They concluded that regulatory focus staff are driven by their internal motivation, and their behavior is mainly affected by personal interests, aspirations and dreams, so regulatory focus staff tend to form the affective commitment; While prevention focus employees are affected by external motivation, and they are mainly affected by external pressure, so prevention focus employees are more likely to form normative commitment and continuous commitment by doing their best to comply with social norms. This conclusion were proved by further empirical study of Markovits, Ullrich, Van-Dick and Davis (2008).

Work Performance. The study of Wallace and Chen (2006) found that the workers' promotion focus and prevention focus can promote the production performance and safety performance separately. Employees with high promotion focus are able to finish their work more efficiently, quickly and efficiently, while employees with high prevention focus can do their work more accurately and safe. Wu Zhiming (2013) discussed the influences of leader and subordinate's regulation focus on subordinate's task performance and contextual performance. The results show as follows: 1) subordinate's prevention promotion focus has significant influences both on interpersonal facilitation and job performance in the situation performance, while subordinate's prevention focus just has significant impacts on the task performance; 2) leader's promotion focus has significant effects on his subordinates' interpersonal facilitation in contextual performance, and leader's prevention focus leader matters subordinates' task performance a lot; 3) The matched promotion focus between leaders and their subordinates is adjusted by the mediating role of leader-subordinate exchange in subordinates' contextual performance.

Creativity and Innovation. Wu et al. (2008) found that leader's promotion focus has the positive predictions of subordinates' creativity, while there was no significant relationship between prevention focus and creativity through the investigation about 191 employees of the manufacturing enterprises. Through further longitudinal study, Henker, Sonnentag, and Unger (2015) found that promotion focus can stimulate workers' creativity by promoting their abilities on problem identification, information search, coding. and thus enhance their creativity. In addition, Neubert et al. (2008) found that subordinates' promotion focus has positive prediction of their innovative behavior.

Organizational Citizenship Behavior. Neubert et al. (2008) found that regulation focus is closely related to deviance behavior and helping behavior in work 
situation. Prevention focus has positive prediction of the deviant behavior and promotion focus has positive prediction of helping behavior. Lin and Johnson (2015) studied and examined the relationship between promotion focus and verbal advice behavior of employee through the longitudinal, which found that employee's promotion focus can enhance their increase both promotional and prohibitive verbal advice behavior of employee, while prevention focus can only enhance the worker's prohibitive verbal advice behavior.

\subsection{Regulatory Focus as a Moderator Variable}

Regulatory focus has effects on work behaviors between leader and subordinate. De Cremer, Mayer van, Dijke, Bardes and Schouten (2009) studied the moderating role of prevention focus's effects between Self Leadership (self-sacrificial Leadership) and subordinate prosocial behavior (prosocial behavior) through empirical researches. Regardless of prosocial behavior is measured by himself or by others, the results showed that the higher the level of subordinate's prevention focus, the stronger the relationship between the Self Leadership and his social behavior (cooperation, organizational citizenship behavior). From the aspect of interaction between people and the environment, Graham, Ziegert and Capitano (2015) discusses the effects on subordinates' prosocial organizational unethical behavior (unethical pro-organizational behavior) by the interactive impacts among the leadership style, the information framework used by leadership and the promotion focus.

If subordinate's promotion focus level is low, regardless of the information framework used by leadership is "gained" or "lost", there were no significant differences about the parent organization of unethical behavior of transformational leadership and transactional leadership. But when subordinate's promotion focus level is high, if the information framework used by leadership is "lost", leading to the use of "loss" framework, the parent organization of unethical behavior of transformational leadership will significantly higher than that of transactional leadership.

Regulatory focus has moderating effects between leadership and subordinates' job performance. Stam, Van Knippenberg and Wisse (2010) explored communication of vision's impacts on the subordinate's job and the moderating role of promotion focus. They believe that vision communication can give subordinate the chance to create an ideal self, which can motivate themselves to implement it; And this can be more a conducive process for subordinate's improvement on work performance of subordinates when subordinate become the core of the vision. Vision communication's promotional effects on job performance of is more obvious when employees have high promotion focus. Li Lei, Shang Yu Ming Xi V, (2012) found that subordinate's idiosyncratic regulatory focus can adjust the relationship between situational regulatory focus and subordinate's creativity. When subordinate's promotion focus is high, situational promotion regulatory focus has stronger positive influence on creativity, and situational prevention regulatory focus has weaker negative impacts on creativity. Li Lei, et 
al. (2012) also tested the leadership's feedback titer, feedback style and subordinate's regulatory focus's three-interaction effects on employees' creativity.

The results shows that when subordinate with high promotion focus received successful feedback of promotional leadership, they tend to show the highest creativity level. In addition, Lei Xinghui, Wen Zhi Shan, Su Taoyong, Yang Yuanfei (2015) also examined the interactive effects between humble leadership and regulatory focus. They found that the stronger tendency of subordinate promotion focus, the stronger positive effects on subordinate's self-efficacy of humble leadership. If subordinate has stronger prevention focus, humble leadership can have stronger enhancement on subordinates' psychological security. is strong, and subordinates' creativity as well.

Regulatory focus has moderating effects between leadership and subordinates' work attitude. Pierro, Cicero and Higgins (2009) tested promotion focus's moderating role between leaders group prototypicality and subordinates' satisfaction. Leaders' group prototypicality refers to the degree tht a team leader can their team or organization's (Hogg, 2001). The results showed that the higher the promotion focus subordinate has, the stronger positive relationship between $t$ Leaders' group prototypicality and subordinates' satisfaction. Hamstra, Yperen, Wisse and Sassenberg (2011) discusses the relationship among transformational leadership, transactional leadership, regulatory focus and turnover intention. The results shows that transformational leadership's negative effects on turnover intention only appears in the high promotion focus situation, while transactional leadership's negative effects on turnover intention only appears in the high prevention focus situation. Voigt and Hirst (2015) examined the moderating effect of promotion focus on employee job performance and turnover intention, which found that the higher promotion focus is, the stronger negative effects of job performance on turnover intention. Shi Qing (2011) introduced regulatory focus into the study of the effectiveness of leadership behavior and discussed the influences of the transformational leadership's interactive effects on subordinates' job satisfaction and organizational commitment.

The results showed that higher promotion focus is, the more it is likely to weaken positive effects of transformational leadership's satisfaction level and organizational commitment; while the higher prevention focus is, it is more likely to enhance the positive effects of transformational leadership's satisfaction level and organizational commitment.

\section{Conclusions}

Just as regulatory focus theory has much to say about employees' emotions, work attitude, and behaviors, the study of the antecedents and consequences of people's tendencies to be promotion versus prevention mostly focused in work settings refine and extended our understanding of regulatory focus theory. Recent researches on the theory of regulatory focus not only promote the exploration of its internal mechanism, but also helpful to apply the theory to the field of interpersonal interaction, organization management, marketing, and so on, so as 
to improve interpersonal relationships, organizational efficiency, and sales performance.

However, most of the recent research has been performed based on studies taken college students as research objects, and mainly used experimental method, and the experimental situation involved is some abstract task, so the results of these studies whether can be applied in real life is also questionable. In addition to evaluating the generalizability of regulatory focus theory to the organizational arena, future research needs to investigate how organization related factors influence regulatory focus processes. Since self-regulation is influenced by the culture of the individual, it is necessary to focus on the researches in different cultural contexts. Some researches about this theory are certainly worth further exploration particularly the in specific cultural background.

\section{References}

Brockner, J., \& Higgins, E. T. (2001). Regulatory Focus Theory: Implications for the Study of Emotions at Work. Organizational Behavior and Human Decision Processes, 86, 35-66. https://doi.org/10.1006/obhd.2001.2972

De Cremer, D., Mayer, D. M., van Dijke, M., Schouten, B. C., \& Bardes, M. (2009). When Does Self-Sacrificial Leadership Motivate Prosocial Behavior? It Depends on Followers' Prevention Focus. Journal of Applied Psychology, 94, 887-899.

https://doi.org/10.1037/a0014782

Dholakia, U. M., Gopinath, M., Bagozzi, R. P., \& Nataraajan, R. (2006). The Role of Regulatory Focus in the Experience and Self-Control of Desire for Temptations. Journal of Consumer Psychology, 16, 163-175.

https://doi.org/10.1207/s15327663jcp1602_7

Gorman, C. A., Meriac, J. P., Overstreet, B. L., Apodaca, S., McIntyre, A. L., Park, P., \& Godbey, J. N. (2012). A Meta-Analysis of the Regulatory Focus Nomological Network: Work-Related Antecedents and Consequences. Journal of Vocational Behavior, 80, 160-172.

Graham, K. A., Ziegert, J. C., \& Capitano, J. (2015). The Effect of Leadership Style, Framing, and Promotion Regulatory Focus on Unethical Pro-Organizational Behavior. Journal of Business Ethics, 126, 423-436.

https://doi.org/10.1007/s10551-013-1952-3

Gray, J. A. (1990). Brain Systems That Mediate Both Emotion and Cognition. Cognition \& Emotion, 4, 269-288. https://doi.org/10.1080/02699939008410799

Hamstra, M. R., Van Yperen, N. W., Wisse, B., \& Sassenberg, K. (2011). Transformational-Transactional Leadership Styles and Followers' Regulatory Focus. Journal of Personnel Psychology, 10, 182-186. https://doi.org/10.1027/1866-5888/a000043

Henker, N., Sonnentag, S., \& Unger, D. (2015). Transformational Leadership and Employee Creativity: The Mediating Role of Promotion Focus and Creative Process Engagement. Journal of Business and Psychology, 30, 235-247. https://doi.org/10.1007/s10869-014-9348-7

Higgins, E. T. (1997). Beyond Pleasure and Pain. American Psychologist, 52, 1280-1300. https://doi.org/10.1037/0003-066X.52.12.1280

Higgins, E. T. (1998). Promotion and Prevention: Regulatory Focus as a Motivational Principle. Advances in Experimental Social Psychology, 30, 1-46.

Higgins, E. T., Friedman, R. S., Harlow, R. E., Idson, L. C., Ayduk, O. N., \& Taylor, A. 
(2001). Achievement Orientations from Subjective Histories of Success: Promotion Pride versus Prevention Pride. European Journal of Social Psychology, 31, 3-23.

https://doi.org/10.1002/ejsp.27

Johnson, P. D., Shull, A., \& Wallace, J. C. (2011). Regulatory Focus as a Mediator in Goal Orientation and Performance Relationships. Journal of Organizational Behavior, 32, 751-766. https://doi.org/10.1002/job.701

Kark, R., \& Van-Dijk, D. (2007). Motivation to Lead, Motivation to Follow: The Role of the Self-Regulatory Focus in Leadership Processes. Academy of Management Review, 32, 500-528. https://doi.org/10.5465/AMR.2007.24351846

Lei, X., Shan, Z., Su, T., \& Yang, Y. (2015). The Impact of Humble Leadership on Employee Creativity. Management Science, 28, 115-125.

Lin, S. H. J., \& Johnson, R. E. (2015). A Suggestion to Improve a Day Keeps Your Depletion Away: Examining Promotive and Prohibitive Voice Behaviors within a Regulatory Focus and Ego Depletion Framework. Journal of Applied Psychology, 100, 1381-1397. https://doi.org/10.1037/apl0000018

Lockwood, P., Jordan, C. H., \& Kunda, Z. (2002). Motivation by Positive or Negative Role Models: Regulatory Focus Determines Who Will Best Inspire Us. Journal of Personality and Social Psychology, 83, 854-864.

https://doi.org/10.1037/0022-3514.83.4.854

Markovits, Y., Ullrich, J., Van-Dick, R., \& Davis, A. J. (2008). Regulatory Focus and Organizational Commitment. Journal of Vocational Behavior, 73, 485-489.

Meyer, J. P., Becker, T. E., \& Vandenberghe, C. (2004). Employee Commitment and Motivation: A Conceptual Analysis and Integrative Model. Journal of Applied Psychology, 89, 991-1007. https://doi.org/10.1037/0021-9010.89.6.991

Neubert, M. J., Kacmar, K. M., Carlson, D. S., Chonko, L. B., \& Roberts, J. A. (2008). Regulatory Focus as a Mediator of the Influence of Initiating Structure and Servant Leadership on Employee Behavior. Journal of Applied Psychology, 93, 1220-1233. https://doi.org/10.1037/a0012695

Pierro, A., Cicero, L., \& Higgins, E. T. (2009). Followers' Satisfaction from Working with Group-Prototypic Leaders: Promotion Focus as Moderator. Journal of Experimental Social Psychology, 45, 1105-1110.

Sengupta, J., \& Zhou, R. (2007). Understanding Impulsive Eaters' Choice Behaviors: The Motivational Influences of Regulatory Focus. Journal of Marketing Research, 44, 297308. https://doi.org/10.1509/jmkr.44.2.297

Shi, Q. (2011). An Empirical Study on the Effectiveness of Individual Regulation Focus on the Effectiveness of Leadership Behavior. Journal of Southwest University, 37, 117-121.

Stam, D., van Knippenberg, D., \& Wisse, B. (2010). Focusing on Followers: The Role of Regulatory Focus and Possible Selves in Visionary Leadership. The Leadership Quarterly, 21, 457-468.

Vaughn, L. A., Baumann, J., \& Klemann, C. (2008). Openness to Experience and Regulatory Focus: Evidence of Motivation from Fit. Journal of Research in Personality, 42, 886-894.

Voigt, E., \& Hirst, G. (2015). High and Low Performers' Intention to Leave: Examining the Relationship with Motivation and Commitment. The International Journal of Human Resource Management, 26, 574-588. https://doi.org/10.1080/09585192.2014.922599

Wallace, C., \& Chen, G. (2006). A Multilevel Integration of Personality, Climate, Self-Regulation, and Performance. Personnel Psychology, 59, 529-557.

https://doi.org/10.1111/j.1744-6570.2006.00046.x 
Wu, C., McMullen, J. S., Neubert, M. J., \& Yi, X. (2008). The Influence of Leader Regulatory Focus on Employee Creativity. Journal of Business Venturing, 23, 587-602.

Yao, Q., \& Yue, G. (2009). The New Development of Motivation Theory: Regulatory Focus Theory. Advances in Psychological Science, No. 6, 1264-1273.

Submit or recommend next manuscript to SCIRP and we will provide best service for you:

Accepting pre-submission inquiries through Email, Facebook, LinkedIn, Twitter, etc. A wide selection of journals (inclusive of 9 subjects, more than 200 journals)

Providing 24-hour high-quality service

User-friendly online submission system

Fair and swift peer-review system

Efficient typesetting and proofreading procedure

Display of the result of downloads and visits, as well as the number of cited articles Maximum dissemination of your research work

Submit your manuscript at: http://papersubmission.scirp.org/

Or contact psych@scirp.org 